\title{
DINAMIKA SOSIAL EKONOMI PRIANGAN ABAD KE-19
}

\author{
Mumuh Muhsin Zakaria \\ Program Studi Ilmu Sejarah Fakultas Sastra Universitas Padjadjaran \\ Jalan Raya Bandung-Sumedang km. 21 Jatinangor Email: \\ mumuhmz@unpad.ac.id
}

\begin{abstract}
ABSTRAK. Abad ke-19 bagi Priangan khususnya dan Pulau Jawa umumnya merupakan moment penetrasi kolonial yang sangat intens. Hal ini dilakukan melalui pelibatan hampir sebagian besar komponen masyarakat dalam mengusahakan tanaman komersial yang laku di pasar internasional, seperti nila, kopi, teh, dan kina. Hal tersebut tidak serta-merta mematikan aktivitas perekonomian dan pertanian subsitem penduduk Priangan. Malah yang terjadi adalah hubungan komplementer antar-keduanya. Hal ini dimungkinkan selain karena faktor geografis-ekologis yang kondusif juga karena jenis tanaman yang diusahakan dan jenis tanah yang digunakan tidak menyaingi sektor ekonomi pertanian. Peran elit lokal sangat besar dalam menciptakan keseimbangan dan harmonisasi relasi antar penduduk pribumi, pemerintah kolonial, dan elit lokal sendiri yang pada gilirannya berpengaruh terhadap peningkatan produk dan terciptanya suasana aman. Fakta historis yang ditemukan di Priangan menjadi indikator penting yang menjelaskan derajat relatif kesejahteraan masyarakatnya. Penelitian yang saya lakukan ini menggunakan metode sejarah yang meliputi empat tahapan kerja: heuristik, kritik, interpretasi, dan historiografi.
\end{abstract}

Kata Kunci: Sejarah, Priangan, Ekonomi, Kolonial.

\section{SOCIO-ECONOMIC DYNAMICS AT PRIANGAN IN 19th CENTURY}

ABSTRACT. The nineteenth century in Priangan and Java was a moment of more intensive colonial penetration indicated by the involvement a number of indigenous people to plant commercial crops for international market such as indigo, coffee, tea, and cinchona. That situation did not automatically disturb subsistence agricultural activities. Even, the two sectors had a complementary relationship, which was made possible by geographical and ecological factors. In addition, types of plants and land used for it were not in competition against agricultural economic sector. Local elite played important roles to create the equilibrium and harmonious relations among indigenous people, colonial government, and local elites themselves that in turn had great influence to heighten product and create safe and conducive situation. Historical evidences found within Priangan were important indicators which explained a relative degree of prosperity of indigenous people. Historical method, of course, used to do the study includes four stages of heuristic, critical sources, interpretation, and finally historiography.

Keywords: history, Priangan, Economic, Colonial

\section{PENDAHULUAN}

Pada abad ke-19 hubungan antara kekuasaan tradisional dan kekuasaan Belanda menunjukkan dua gejala yang bertolak belakang. Di satu pihak kekuasaan 
Belanda makin meluas, di lain pihak kekuasaan pribumi makin melemah. Hubungan dengan kekuasaan Barat ini berpengaruh terhadap berbagai segi kehidupan. Dalam bidang politik, pengaruh Belanda makin kuat karena intervensi yang intensif dalam persoalan-persoalan intern kekuasaan pribumi seperti dalam masalah suksesi, promosi, mutasi, dan rotasi pejabat. Dalam bidang ini, penguasapenguasa tradisional makin tergantung pada kekuasaan asing sehingga kebebasan dalam menentukan soal-soal pemerintahan makin melemah. Dalam bidang sosialekonomi kontak dengan Barat berakibat melemahnya kedudukan kepala-kepala daerah dan pemimpin-pemimpin tradisional. Kekuasaan mereka berangsur berkurang dan ditempatkan di bawah pengawasan pejabat-pejabat asing sedangkan tenaga mereka dilibatkan dalam sistem eksploitasi ekonomi kolonial. Keadaan seperti ini menimbulkan kegoncangan dalam kehidupan para penguasa tradisional. Di Jawa faktor-faktor produksi pertanian, baik menyangkut tanah maupun tenaga kerja, diatur sedemikian rupa untuk kepentingan kolonial. Para petani dibebani tugas mengolah sebagian tanahnya untuk ditanami tanamantanaman ekspor dan diharuskan menyumbangkan tenaganya secara paksa pada penguasa kolonial. Dalam bidang budaya, abad ke-19 merupakan momentum makin meluasnya pengaruh kehidupan Barat dalam lingkungan kehidupan tradisional. Hal ini menimbulkan kekhawatiran akan terdesak dan rusaknya nilainilai kehidupan tradisional. Tindakan-tindakan penguasa asing tersebut menimbulkan antipati di kalangan penduduk pribumi yang menuju ke arah timbulnya perlawanan. Oleh karena itu, jumlah gerakan perlawanan yang terjadi di daerah-daerah selama abad ke-19 cukup banyak.

Tidak dapat disangkal lagi bahwa dominasi Barat beserta perubahanperubahan sosial yang mengikutinya telah menciptakan kondisi-kondisi yang memungkinkan rakyat untuk berkecenderungan melakukan pergolakan sosial. Dominasi ekonomi, politik, dan kultural yang terjadi pada masa kolonial telah mengakibatkan timbulnya disorganisasi di kalangan masyarakat tradisional beserta lembaga-lembaganya.

Akar persoalan gerakan-gerakan perlawanan yang dilakukan penduduk terhadap penguasa kolonial tidak disebabkan oleh faktor tunggal seperti memburuknya kondisi ekonomi. Namun, faktor-faktor lain seperti sosial, politik, budaya, dan agama turut serta. Jadi kompleksitas situasi menjadi sebab terjadinya gerakan sosial. Namun demikian, tidak dapat disangkal bahwa memburuknya kondisi ekonomi sering jadi pemicu yang cukup menonjol terjadinya gerakangerakan sosial itu.

Yang menarik perhatian selanjutnya adalah di tengah-tengah generalisasi seperti disebutkan di atas, tampak Keresidenan Priangan sebagai kekecualian. Di wilayah keresidenan ini tidak ditemukan data terjadinya gerakan-gerakan perlawanan.

Penelitian yang dikaji dalam disertasi ini secara spasial meliputi wilayah geografis Priangan, secara temporal dalam lingkup abad ke-19, dan sebagai aktor peristiwa adalah manusia kebanyakan (tidak mengkhususkan pada kelompok sosial tertentu).

Priangan sebagai unit geografis penelitian ini memiliki dua pengertian. Ketika kata keresidenan dilekatkan pada kata Priangan, jadilah ia sebagai nama unit 
administratif pemerintahan yang dipimpin oleh seorang residen dan membawahi sejumlah kabupaten. Pada abad ke-19, kabupaten-kabupaten yang ada di bawah Keresidenan Priangan adalah Cianjur, Bandung, Sumedang, Parakanmuncang, Limbangan, dan Sukapura. Tiga kabupaten yang disebut terakhir ini keberadaannya dan namanya mengalami beberapa kali perubahan. Bahkan kemudian ke dalam keresidenan ini masuk Kabupaten Ciamis (1915), yang semula termasuk Keresidenan Cirebon. Pada sisi lain, melekat pada kata Priangan ini identitas kultural kesundaan. Oleh karena itu, wilayah Priangan pun sering disebut sebagai wilayah Pasundan (tempat tinggal orang-orang Sunda). Rupanya, Pemerintah Kolonial Belanda cukup memperhitungkan kabupaten mana digabungkan dalam satu keresidenan apa, yang dibedakannya dari pengelompokan kabupaten-kabupaten lainnya pada keresidenan yang lain. Salah satu pertimbangannya adalah kriteria kesamaan latar budaya. ${ }^{1}$

Dalam berbagai sumber dicatat bahwa sejak tahun 1900 ekonomi Jawa secara umum dalam keadaan buruk. Kemiskinan dan penderitaan penduduk pribumi sering dilaporkan (van Deventer, 1961: 155). Situasi ini menyebabkan Pemerintah Kolonial melakukan penyelidikan untuk mengetahui merosotnya tingkat kesejahteraan itu. ${ }^{2}$ Hasil dari penyelidikan ini menunjukkan bahwa terdapat hubungan yang jelas antara kondisi sosial-ekonomi masyarakat pada awal abad ke-20 dengan perkembangan-perkembangan yang terjadi pada abad sebelumnya, abad ke-19.

Hal ini, pada gilirannya, akan memunculkan serangkaian pertanyaan sebagai berikut:

1) Apakah kolonialisme itu merupakan faktor tunggal (single factor) yang menyebabkan terjadinya kemiskinan rakyat?

2) Atau, apakah ada faktor lain seperti ikatan tradisional dan praktik feodal yang dilakukan oleh bangsawan pribumi yang membelenggu kehidupan masyarakat?

3) Adakah kebijakan kolonial yang sama yang dipraktikkan di seluruh Jawa atau adakah perbedaan antara satu daerah dengan daerah lainnya?

4) Faktor-faktor apakah yang menyebabkan terjadinya perbedaan-perbedaan itu?

Arti penting Priangan secara historis kurang mendapat perhatian yang sepadan dalam kajian akademis. Tidak banyak sejarawan baik asing maupun domestik menaruh minat pada ekonomi Priangan abad ke-19. Ilmuwan asing terkesan berhenti mengkaji Priangan pada karya-karya yang dikategorikan sebagai klasik $^{3}$; hanya sedikit ilmuwan asing kontemporer yang menaruh perhatian pada

\footnotetext{
${ }^{1}$ Ketika kemudian muncul istilah Provinsi Jawa Barat (West Java) pada tahun 1925, pemerintahan keresidenan yang ada di bawahnya adalah Batavia, Banten, Priangan, dan Cirebon. Kabupatenkabupaten yang masuk ke Keresidenan Priangan adalah yang pekat ciri-ciri kesundaannya. Eksistensi Keresidenan Priangan sebagai unit administratif berlangsung hingga tahun 1964 . Sejak itu istilah keresidenan tidak digunakan lagi; ia kemudian diganti dengan istilah wilayah, yaitu Wilayah V Priangan.

${ }^{2}$ Kondisi-kondisi seperti inilah yang kemudian pada tahun 1902 Ratu Belanda Wilhelmina membentuk sebuah komisi untuk menyelidiki mundurnya kemakmuran (mindere we/vaart) penduduk pribumi. Komisi ini menghasilkan laporan sebanyak 35 volume yang berjudul Onderzoek naar de Mindere Welvaart der Inlandsche Bevolking op Java en Madoera.

3 Karya-karya klasik tentang Priangan di antaranya: Andries de Wilde. 1830. De Preanger regentschappen op Java gelegen. Amsterdam: Westerman; H. J. Hageman "Geschiedenis der Soendalanden," dalam TBG, XVI, hlm. 178-151; XVII, hlm. 178-257; XIX, hlm. 101-169 (1867, 1869,
} 
ekonomi Priangan abad ke-19. ${ }^{4}$ Sementara, sejarawan domestik selain sedikit, juga tidak banyak yang tertarik mengkaji sejarah ekonomi Keresidenan Priangan. Padahal, faktor ekonomi merupakan salah satu kekuatan yang menggerakkan roda sejarah. ${ }^{5}$

Studi ini bertujuan menggambarkan dinamika sosial-ekonomi masyarakat Priangan abad ke-19 dan faktor-faktor kausatif yang membawa perubahan yang terjadi sebagai pengaruh dari penerapan kebijakan pemerintah kolonial. Dari studi ini diharapkan bahwa perbedaan antara pengaruh kebijakan pemerintah kolonial di Priangan dan di wilayah lain di Pulau Jawa sebagai akibat semakin intensifnya pengaruh praktik kolonial dapat tergambarkan baik secara eksplisit maupun implisit.

Oleh karena itu, penulis mengambil tema ekonomi Priangan abad ke-19 untuk penelitian disertasi ini dengan judul Keresidenan Priangan Abad ke-19 dalam Arus Dinamika Sosial-Ekonomi.

\section{METODE}

Untuk mengungkap dinamika kehidupan sosial-ekonomi di Keresidenan Priangan abad ke-19 tampaknya tidak cukup memadai bila hanya secara deskriptifnaratif yang berkisar pada upaya menjawab pertanyaan apa, siapa, di mana, dan kapan. Jawaban atas pertanyaan bagaimana dan mengapa pun harus dieksplisitkan; dan untuk itu diperlukan penjelasan yang bersifat analitis dan struktural.

Bantuan pendekatan ilmu-ilmu sosial seperti antropologi, sosiologi, dan ilmu politik diperlukan karena kajian historis yang bersifat diakronis saja dianggap tidak cukup. Untuk memperoleh gambaran yang utuh perlu dilengkapi dengan analisis secara sinkronis. Dengan cara ini pula eksplanasi historis yang dihasilkan diharapkan cukup memadai.

Untuk meneliti dinamika kehidupan sosial-ekonomi di Keresidenan Priangan abad ke-19 digunakan metode sejarah. Kegiatan yang pertama-tama

dan 1870); Otto van Rees. 1869. Overzigt van de geschiedenis der Preanger regentschappen. Batavia: BGKW; P. de Roo de la Faille. 1895. Preanger schetsen. Batavia: Kolff \& Co., J.D. van Herwerden. 1871. De conferentie te Bandong; afschaffing van het Preanger-stelsel. 's Gravenhage: De la Vieter; Henri Charles van Meerten. 1887. Overzicht van de hervorming van het Preanger-stelsel. Leiden: Groen; F. de Haan. 1910-1912. Priangan; de Preanger-Regentschappen onder het Nederlandsch Bestuur tot 1811. 4 vols. Batavia/'s-Gravenhage: G. Kolff \& Co./Martinus Nijhoff; Jacob Wouter de Klein. 1931. Het Preangerstelsel (1677-1871) en zijn nawerking. Delft: Waltman.

${ }^{4}$ Di antara ilmuwan asing yang menaruh perhatian pada sejarah Priangan abad ke-19 adalah Thommy Svensson, seorang sosiolog berkebangsaan Swedia. Ia menulis "State Bureaucracy and Capitalism in Rural West Java; Local Gentry versus Peasant Entrepreneurs in Priangan in the $19^{\text {th }}$ and $20^{\text {th }}$ Century" yang dimuat dalam Jurnal Nias Report tahun 1991, No. 1, hlm. $1-65$. Jurnal tersebut diterbitkan oleh Nordic Institute of Asian Studies di Copenhagen. Selain itu, Jacques Van Doorn dan Willem J. Hendrix; kedua ilmuwan Belanda ini menulis The Emergence of a Dependent Economy; Consequences of the Opening up of West Priangan, Java, to the Process of Modernization (43 halaman) yang dimuat pada Jurnal CASP edisi tahun 1983 yang diterbitkan di Rotterdam.

${ }^{5}$ Dua sejarawan perlu disebut di sini adalah Nina Herlina Lubis dan A. Sobana Hardjasaputra. Yang pertama memfokuskan kajian pada kelompok sosial tertentu, yaitu kaum menak sebagaimana tampak pada judul disertasinya "Kehidupan Kaum Menak Priangan 1800-1942", sementara yang kedua memusatkan perhatian pada kajian bupati melalui tesisnya berjudul "Bupati Priangan; Kedudukan dan Peranannya". 
dilakukan adalah mencari dan mengumpulkan sumber baik primer maupun sekunder. Sumber primer adalah berupa arsip-arsip kolonial, khususnya arsip-arsip Priangan abad ke-19. Sumber tersebut tersimpan di Arsip Nasional Republik Indonesia (ANRI) di Jakarta dan di Negeri Belanda. Arsip-arsip Kolonial di Negeri Belanda didapatkan di dua tempat, yaitu di Nationaal Archief, The Hague dan di KITLV, Leiden, serta koleksi-koleksi pribadi. Selain arsip kolonial, sumber primer pun berupa buku-buku klasik yang ditulis oleh aktor sejarah pada zamannya dan dokumen-dokumen tercetak. Selain itu, sumber-sumber lain seperti monografi, artikel, dan ensiklopedi (Encyclopaedie van Nederlandsch-Indie) juga digunakan.

Sumber-sumber sekunder yang digunakan terdiri atas tiga kategori sumber. Pertama, sumber yang secara substantif mengkaji lingkup spasial Priangan. Dari buku jenis ini, baik berupa sumber tradisional maupun modern, diperoleh informasi mengenai Priangan. Yang termasuk sumber modern di sini adalah sumber yang ditulis secara ilmiah yang secara implisit dan eksplisit menggambarkan kondisi sosial, ekonomi, dan budaya masyarakat Priangan. Kategori kedua meliputi sumber-sumber komparatif, yaitu buku yang secara spasial tidak membahas Priangan, tetapi memiliki tema dan issue mirip dengan tema disertasi ini yaitu sosial-ekonomi. Kategori ketiga adalah buku referensi umum yang mendiskusikan kondisi sosial-ekonomi Jawa abad ke-19. Selain di Belanda dan di Arsip Nasional Jakarta, sumber-sumber didapatkan juga di beberapa perpustakaan di Jerman (Staadtsbibliothek zu Berlin-Preussischer Kulturbesitz, Universitätsbibliothek der Humboldt-Universität zu Berlin, Universitätsbibliothek Passau), Perpustakaan Nasional Jakarta, dan koleksi-koleksi pribadi. Terhadap sumber yang diperoleh dilakukan kritik baik internal maupun eksternal. Setelah itu dilanjutkan dengan interpretasi fakta. Analisis kualitatif dan kuantitatif pun dilakukan.

Untuk mendapatkan gambaran yang jelas mengenai kondisi sosial-ekonomi masyarakat Priangan abad ke-19, analisis yang dilakukan dalam studi ini berfokus pada tiga hal, yaitu perkembangan demografi, perkembangan ekonomi, dan peran elit tradisional yang berperan sebagai mediator dan penerjemah kebijakankebijakan pemerintah kolonial terhadap rakyatnya. Sejumlah sumber referensi cukup memfasilitasi pelaksanaan analisis terhadap variabel-variabel di atas. Salah satu di antaranya adalah 16 jilid buku Changing Economy in Indonesia yang diedit oleh Peter Boomgaard (1987). ${ }^{6}$

Pada tahap yang terakhir dilakukan rekonstruksi berupa tulisan sejarah (historiografi). Dalam historiografi ini sebisa mungkin diamalkan kaidah-kaidah penulisan yang ilmiah, dan pada saat yang sama diperhatikan pula aspek kronologis, kausalitas, dan logika dengan tetap setia pada fakta.

\section{HASIL DAN PEMBAHASAN}

\footnotetext{
${ }^{6}$ Keenambelas jilid buku yang dibuat atas inisiatif W.M.F. Mansvelt dan dilanjutkan oleh P. Creutzberg kemudian diedit oleh Peter Boomgaard ini terdiri atas seri-seri sebagai berikut: Indonesia's Export Crops 1816-1940, Public Finance 1816-1939, Expenditure of Fixed Assets, Rice Prices, National Income, Money and Banking 1816-1940, Balance of Payments 1822-1939, Manufacturing Industry 1870-1942, Transport 1819-1940, Foodcrops and Arable lands Java 1815-1940, Population Trends 1795-1942, Trade Statistics 1823-1940, Regional Patterns in Foreign Trade 1911-1940, Wages 1820-1940, Price (non-rice), Cultivation System, dan Forestry.
} 
Penilaian bahwa kesejahteraan ekonomi penduduk Jawa merosot, secara faktual, merupakan generalisasi yang dapat diperdebatkan. Dalam kasus Priangan tidak ditemukan data yang dapat membuktikan tentang buruknya kondisi ekonomi rakyat. Secara hipotesis, paling tidak, pada periode intensifikasi itu, kondisi ekonomi masyarakat Priangan secara umum cenderung baik. Hipotesis semacam ini didasarkan pada fakta bahwa di Priangan tidak terdapat laporan tentang kasus kelaparan, pemberontakan, kerusuhan sosial, migrasi ke luar besar-besaran, dan semacamnya yang mengindikasikan buruknya kesejahteraan ekonomi (periksa Kartodirdjo, 1973; $1984^{1}$, 1984² 1987 ; Cf. Suryo, 1988; Suhartono, 1991). Para peneliti seperti Gonggrip (1957), Boeke (1942), Burger (1848/1849; 1975) menegaskan bahwa telah terjadi proses kemunduran tingkat kemakmuran pendudukan Jawa pada abad ke-19 akibat dari kebijakan pemerintah dalam bidang sosial dan ekonomi serta semakin dalamnya tingkat penetrasi Barat. Lebih tegas lagi, Fernando (1980) menyebutkan bahwa telah terjadi kelaparan yang melanda Cirebon tahun 1844 - 1850 dan beberapa tempat lain di Jawa Tengah (Elson, 1994: 301 - 322), seperti Semarang (1826), Rembang (1829), Pekalongan, dan Bagelen (1830).

Informasi seperti itu didasarkan pada sejumlah sumber. Misalnya, dalam buku Sejarah Nasional Indonesia, jilid IV, yang secara khusus meliput sejarah Indonesia abad ke-19. Bab III buku ini, yang menguraikan gerakan-gerakan perlawanan terhadap kolonialisme, tidak mengungkap informasi tentang adanya gerakan-gerakan melawan kolonialisme di Priangan. Pada bab IV, yang mendiskusikan gerakan-gerakan sosial (social movements), diterangkan gerakangerakan seperti itu hanya terjadi di Jawa Tengah dan Jawa Timur. Adapun yang terjadi di Jawa Barat hanya terdapat di daerah-daerah Batavia, Banten, Cirebon, dan di tanah-tanah partikelir (partikuliere landerijen), yang kesemua itu tidak menjadi bagian dari Keresidenan Priangan (Periksa Leirissa ed., 1993: 147-353; Kartodirjo, 1987: 370-392). Terjadinya peristiwa semacam itu di wilayah-wilayah tersebut dipicu oleh memburuknya kondisi ekonomi. ${ }^{7}$ Sartono Kartodirdjo (1973), misalnya, dalam karya monumentalnya tentang gerakan-gerakan protes di Jawa yang berjudul Protest Movement in Rural Java; a Study of Agrarian Unrest in the Nineteenth and Early Twentieth Centuries dengan ketebalan 229 halaman hanya lima kali menulis kata Prijangan. Dua di antaranya tidak dalam konteks gerakan protes; sedangkan tiga sisanya hanya disimpan di foot-note. Hal ini menjadi isyarat bahwa di Priangan tidak ada gerakan protes yang berarti. Begitu pula halnya dalam buku Sartono Kartodirdjo yang berjudul Ratu Adil (Jakarta: Sinar Harapan, 1984).

Selanjutnya, Edi S. Ekadjati et al. (1982/1983) menulis sebuah buku, yang secara khusus membahas gerakan perlawanan di Daerah Jawa Barat, berjudul Sejarah Perlawanan terhadap Kolonialisme dan Imperialisme di Daerah Jawa Barat. Dalam bab III, berjudul "Perlawanan dalam Abad ke-19", dibahas enam kasus gerakan perlawanan; empat di antaranya terjadi di luar Keresidenan Priangan, dua

\footnotetext{
${ }^{7}$ Kalaupun di Priangan terdapat "gerakan", itu bukan karena tekanan faktor ekonomi, tapi lebih bersifat politis, yaitu intervensi pemerintah kolonial dalam suksesi kepemimpinan di tingkat lokal seperti dalam kasus Raksapradja.
} 
sisanya di Priangan. Namun, kedua kasus itu pun selain kecil juga tidak berkait langsung dengan persoalan ekonomi (yaitu kasus Raksapraja tahun 1842 dan kasus Nyi Aciah tahun 1870).

\section{SIMPULAN DAN SARAN}

Priangan abad ke-19 bukan lagi issue lokal, tapi sudah masuk orbit persoalan regional, bahkan internasional. Semua itu terjadi karena komoditas yang dihasilkan Priangan yang laku di pasar internasional. Nila, kopi, teh, dan kina merupakan empat produk unggulan yang berasal dari Priangan pada abad ke-19, di samping produk lainnya yang masuk kategori bukan produk unggulan (minor crops), seperti katun, murbai (sutra), cengkih, lada, tembakau, dan sebagainya.

Keterlibatan Priangan dalam ekonomi kolonial ini memberi keuntungan kepada semua pihak. Petani untung dari hasil penjualan produk pertanian dan upah kerja, bupati untung dari cultuur procenten. Tentu saja yang paling besar mendapat keuntungan adalah pihak kolonial. Pelibatan Priangan dalam arus ekonomi global ini bahkan telah mengakselerasi dan mendinamisasi kehidupan sosial-ekonomi masyarakatnya. Petani, dalam batas tertentu mengalami surplus finansial. Pengaruh lanjut dari adanya surplus finansial ini adalah munculnya tuntutantuntutan akan peningkatan kualitas hidup. Tuntutan-tuntutan itu dijawab dengan bermunculannya warung dan pasar sebagai simbol adanya kegairahan dalam aktivitas perekonomian, dibangunnya berbagai prasarana dan sarana transportasi serta infrastruktur lainnya, berdirinya industri-industri bahan bangunan, meningkatnya tuntutan prasarana dan sarana pendidikan, dan sebagainya.

Meskipun pengerahan tenaga kerja penduduk Priangan sangat gencar untuk meningkatkan produk pertanian berorientasi ekspor, namun ternyata pertanian subsisten tidak terkorbankan. Padi dan aneka ragam palawija tetap berproduksi, bahkan menonjol berkat peningkatan luasan sawah secara kualitas pengolahannya. Oleh karena itu, masyakarat Priangan abad ke-19 tidak bisa disebut lagi sebagai masyarakat peladang (pahuma). Sejak periode ini, masyarakat Priangan adalah masyarakat pesawah, bahkan selama beberapa tahun di abad ke-19 menjadi produsen terbesar padi di Pulau Jawa sehingga bisa "mengekspor" beras ke keresidenan tetangga. Dengan demikian, dalam kasus Priangan, relasi antara ekonomi pertanian dan ekonomi perkebunan bersifat simbiosis mutualistis, bukan simbiosis parasitis.

Priangan abad ke-19 memiliki signifikansi tersendiri bagi Pemerintah Kolonial. Melalui nila, kopi, teh, kina, dan tanaman ekspor lainnya Priangan menjadi penyumbang terbesar bagi perbendaharaan ekonomi Negeri Belanda. Pada sisi lain, penduduk Priangan pun mendapatkan "rembesan" manfaatnya.

Kondisi di Priangan abad ke-19 sangat berbeda dengan wilayah lain di Pulau Jawa. Kondisi sosial-ekonomi masyarakat Priangan adalah cukup baik. Kondisi seperti itu terjadi karena hal-hal berikut ini. Kebijakan Preangerstelsel hanya mewajibkan petani Priangan menanam kopi khusus di tanah dataran tinggi yang tidak digarap dan mereka diwajibkan menjual hasil panen kopi kepada Pemerintah Kolonial dengan harga yang telah ditetapkan. Oleh karena itu, petani dibebaskan 
dari membayar pajak ${ }^{8}$ kepada pemerintah. Praktik Preangerstelse/ dilaksanakan oleh bupati dan elit lokal lainnya dengan memanfaatkan sistem feodal yang ada. Hal ini secara kebetulan menguntungkan rakyat karena mereka dipimpin oleh bupati-bupati yang peduli dengan kesejahteraan rakyat. Sistem feodal di Priangan berbeda dengan yang terjadi di Jawa Tengah, khususnya di Vorstenlanden, Yogyakarta dan Surakarta. Di Priangan feodalitasnya lebih "cair" karena tidak terdapat lembaga kerajaan yang masih berdiri. Selain itu, prilaku penguasa dan elit lokalnya pun memiliki "kesalehan" sosial sebagai ekspresi dari karakter kesantriannya. ${ }^{9}$

Jenis tanaman dan tanah yang digunakan untuk eksploitasi kolonial pun berbeda dari wilayah-wilayah lain di Pulau Jawa. Tanaman kopi, teh, dan karet ditanam di tanah liar seperti hutan dan bukit. Hal ini tidak mengganggu pertanian padi rakyat. Jadi, daerah tanam untuk jenis tanaman seperti itu menjadi semacam enclave dalam sistem pertanian di seluruh Priangan. Hal ini berbeda dengan apa yang terjadi di Jawa Tengah dan Timur di mana tanaman musiman seperti tebu, indigo, dan tembakau ditanam di sawah, saling berselang dengan tanaman padi. Sistem seperti ini menuntut regulasi yang baik berkaitan dengan sistem irigasi, rotasi peruntukan lahan sawah, dan tenaga kerjanya. Hal seperti ini telah mengganggu penanaman padi dan menguras tenaga buruh (exhausted labor).

Mempertimbangkan keuntungan yang diperoleh dari Preangerstelsel, Pemerintah Kolonial berkepentingan memelihara dan menjaga keberlanjutan proses produksi melalui sistem ini. Oleh karena itu, Pemerintah Kolonial melakukan "protective policy" atas rakyat atau pekerja sehingga melindungi mereka seandainya ada tindakan sewenang-wenang dari pemimpin tradisional.

Untuk meningkatkan keuntungan yang diperoleh dari tanaman kopi, Pemerintah kolonial terus memperluas area penanaman. Meningkatnya luas tanaman kopi menuntut tenaga kerja yang banyak dan fasilitas transportasi. Tuntutan akan tenaga kerja memicu terjadinya migrasi-masuk berskala besar (inmigration) ke Priangan. Akibatnya, Keresidenan Priangan mengalami perubahan demografis yang menopang transformasi agronomi saat itu. Meningkatnya produksi kopi dan tanaman lainnya mempengaruhi tuntutan akan keberadaan prasarana dan sarana transportasi yang pada gilirannya menyebabkan tuntutan impor binatang beban seperti kerbau, sapi, dan kuda ke Priangan; juga perbaikan kondisi jalan. Keberhasilan Preangerstelsel membawa pengaruh positif pada meningkatnya kesejahteraan rakyat.

Di samping hal-hal tersebut di atas, ada faktor lain, yaitu perkembangan agama Islam dan hubungannya dengan perubahan sosial-ekonomi di Priangan. Kehidupan keagamaan di Priangan pada permulaan abad ke-19 mengindikasikan gambaran yang menarik dan unik. Pertama, mayoritas masyarakat Priangan adalah

\footnotetext{
${ }^{8}$ Di sejumlah tempat beban pajak sering jadi pemicu terjadinya gerakan-gerakan perlawanan.

${ }^{9}$ Sartono Kartodirdjo (1973: 116) menjelaskan bahwa priayi di Jawa itu abangan; sementara di Banten dan Priangan hampir semua priayi adalah santri. Ia, lebih lanjut, menjelaskan "abangan people after identifying themselves as professing the Buddha - 'religion', although it has nothing to do with Buddism. In many areas of Java the prijaji could be identified as abangan, while in Banten and Priangan almost all prijajis were santri". Cf. Geertz (1960), passim; lihat juga Snouck Hurgronje (1924), vol. IV, part 2, hlm. 111-249.
} 
beragama Islam. Kedua, terdapat banyak lembaga keagamaan seperti masjid, pesantren, dan haji. Ketiga, tumbuhnya tradisi sufisme dan tarekat (thoriqoh). Pada periode ini hampir terjadi identifikasi yang generalistik bahwa "Sunda adalah Islam". Identifikasi seperti ini berlanjut pada periode-periode berikutnya.

Sejumlah bupati Priangan berpendidikan pesantren. Bahkan beberapa di antaranya sebagai pengamal tarekat, malahan ada juga yang jadi guru tarekat, seperti Bupati Cianjur dan Bupati Sumedang. Uniknya adalah bahwa di wilayah lain di luar Priangan, lembaga tarekat sering menampilkan diri sebagai institusi oposan terhadap Pemerintah Kolonial. Tarekat sering tampil sebagai "ideologi" yang bisa menghimpun kekuatan rakyat (people's power) untuk menentang Pemerintah Kolonial. Pemandangan berbeda muncul di Priangan, lembaga-lembaga sufi dan tarekat menunjukkan sikap "kooperatifnya". Kondisi ini terjadi karena kenyataan bahwa kehidupan ekonomi masyarakat Priangan cukup baik.

Keresidenan Priangan abad ke-19 mencerminkan banyak hal sebagai akibat dari semakin intensifnya penetrasi kolonial dalam berbagai sisi kehidupan. Secara politik, keresidenan ini berada di bawah dominasi kekuasaan asing, yakni Pemerintah Hindia Belanda. Namun demikian, keberadaan birokrasi pemerintahan lokal pun tetap diakui eksistensinya karena Pemerintah Kolonial Belanda menerapkan sistem pemerintahan tidak langsung. Jadi, di wilayah ini terdapat dualisme kekuasaan dengan berbagai konsekuensinya. Kemudian, secara ekonomi, keresidenan ini dijadikan sebagai wilayah eksploitasi untuk sebesar-besar kepentingan ekonomi negeri induk melalui ekonomi perkebunan. Pada sisi lain, ekonomi tradisional pun keberadaannya tetap dikembangkan. Secara sosial, akibat dari kontak politik dan ekonomi terjadi perubahan-perubahan sosial terutama dalam bidang demografis, mobilitas sosial, prasarana dan sarana kehidupan, monetisasi, domestikasi penduduk, dan sebagainya.

Masalah penetrasi politik dan administrasi pemerintahan dengan berbagai tampilannya hanyalah alat untuk mengoptimalkan pencapaian target-target ekonomi. Adapun kebijakan politik dan administrasi pemerintahan lebih merupakan taktik yang dalam praktiknya bisa berubah-ubah sesuai dengan situasi dan kondisi; sedangkan kepentingan ekonomi - yakni meraih keuntungan ekonomi sebesarbesarnya bagi negara induk - adalah strategi yang hampir abadi.

Indikator-indikator meningkatnya daya ekonomi dan kesejahteraan rakyat di Priangan ini adalah makin dinamisnya mobilitas sosial (horisontal maupun vertikal), meningkatnya jumlah penduduk sebagai konsekuensi dari naiknya angka kelahiran dan menurunnya angka kematian serta meningkatnya migrasi masuk, rendahnya angka kriminalitas, tidak terjadinya gerakan pemberontakan dan kerusuhan lain, tidak terdapatnya bencana kelaparan, dan sebagainya. 


\section{DAFTAR PUSTAKA}

Arsip

Algemeene Verslag van Preanger-Regentschappen Priangan 1828 - 1888. 1829, $A D$, Priangan, ANRI.

Archive Minister van Kolonien, 1850-1900 (Inv. Nr. 27) 14 February 1856, ARA.

Archive Minister van Kolonien, 1850-1900 (Inv. Nr. 491), 14 February 1856, ARA.

Arsip Koleksi Raden Djenal Asikin Widjaja Koesoema. Museum Geusan Ulun, Sumedang.

"Geheim Politiek Verslag der Residentie Preanger Regentschappen over het Jaar 1865, Preanger 1/11, 1865, ANRI.

Nota van den Resident Overstrand, 5/2 1849 (ANRI Archieven Cultures, no. 294).

"Preanger Statistiek 1836", Preanger 7/1, 1836, ARNAS.

Preanger Statistiek, Preanger 7/1 1839.

"Rapport van den staat der indigo-kultuur en fabrikatie in de PreangerRegentschappen in 1835".

Rapport-grondrecht, dl. 1, hlm. 45, bijl. C.

Rekapitulatie Statistiek der Residentie Preanger Regentschappen 1864.

"Statistiek der Residentie Preanger Regentschappen 1837", Preanger 29a/1, 1837, ANRI.

\section{Dokumen Resmi Tercetak}

Bes/uit 25 September 1836, no. 87.

Bes/uit 8 July 1837, no. 2.

Daghregister tanggal 18 Agustus 1694.

Eindresume van het bij Goevernements bes/uit dd. 10 Juni 1867 No. 2 bevolen Onderzoek naar de Rechten van den Inlander op den Grond op Java en Madoera. Zamengesteld door den Chef der Afdeeling Statistiek ter Algemeene Secretarie. Eerste Gedeelte. Batavia - Ernst \& Co., 1876, bijlage A.

Indische Staatsblad. 1833, no. 7.

Koloniaal Verslag, 1834 - 1898.

Onderzoek Welvaart Priangan 1904/1905. Onderzoek naar de Mindere Welvaart der Inlandsche Bevolking op Java en Madoera: Regentschapsverslagen, Priangan, Batavia 1906-1911. 
Onderzoek naar de Mindere Welvaart der Inlandsche Bevolking op Java en Madoera, dl. Ixc (Batavia, 1911), bijl. 10: 134.

Staatsblad van Nederlandsch-Indie 1853, No. 53.

\section{Buku}

Alisjahbana, Samiati. 1954. A Preliminary Study of Class Structure among the Sundanese in the Prijangan. Tesis unpublished. New York: Cornell University.

Van Baardewijk, Frans. 1993. The Cultivation System, Java 1834 - 1880, Changing Economy in Indonesia. Volume 14. Amsterdam: Royal Tropical Institute.

Boomgaard, Peter. 1989. Between Sovereign Domain and Servile Tenure: The Development of Rights to Land in Java 1780-1870. Amsterdam: Free University Press.

1989. Children of the Colonial State; Population Growth and Economic Development in Java 1795-1880. Amsterdam: Free University Press.

Boomgaard, Peter dan J.L. van Zanden. 1990. Food Crops and Arable Land, Java 1815-1942, Changing Economy in Indonesia. Vol. 10. Amsterdam: Royal Tropical Institute.

Boomgaard, P. and A.J. Gooszen. 1991. Population Trends 1795-1942, Changing Economy in Indonesia; Vol. 11. Amsterdam: Royal Tropical Institute, KIT.

Booth, Anne. 1988. Agricultural Development in Indonesia. Sydney: Allen and Unwin.

Booth, Anne et al. (eds.). 1988. Sejarah Ekonomi Indonesia. Terjemahan Mien Joebhaar. Jakarta: LP3ES.

Booth, Anne. 1998. The Indonesian Economy in the Nineteenth and Twentieth Centuries; A History of Missed Opportunities. London: Macmillan Press.

Bulbeck, David et al. 1998. Southeast Asian Exports since the $14^{\text {th }}$ Cloves, Pepper, Coffee, and Sugar. Singapore: Institute of Southeast Asian Studies.

Burger, D.H. 1957. Sedjarah Ekonomis Sosiologis Indonesia. Terjemahan. Jilid I, Cetakan ketiga. Jakarta: Pradnjaparamita.

Boeke, J.H. dan D.H. Burger. 1973. Ekonomi Dualistis; Dialog Boeke dan Burger. Terjemahan Bhrtara. Jakarta: Bhratara.

Burger, D.H. 1983. Perubahan-perubahan dalam Struktur Masyarakat Jawa. Terjemahan Bhratara. Jakarta Bhratara. 
Clarance-Smith, William Gervase dan Steven Topik. 2003. Coffee Economy in Africa, Asia, and Latin America, 1500-1898. Cambridge University Press.

Ekadjati, Edi S. 1981. Historiografi Priangan. Bandung: Lembaga Kebudayaan Universitas Padjadjaran.

Ekadjati, Edi S. et al. 1982/1983. Sejarah Perlawanan terhadap Kolonialisme dan Imperialisme di Daerah Jawa Barat. Jakarta: Departemen Pendidikan dan Kebudayaan, Direktorat Sejarah dan Nilai Tradisional, Proyek Inventarisasi dan Dokumentasi Sejarah Nasional

Elson, R.E. 1994. Village Java under the Cultivation System 1830-1870. Sydney: Allen and Unwin.

Fernando, M.R. 1980. "Famine in Cirebon Residency in Java 1844 - 1850; a New Perspective on the Cultivation System", Working Papers; Centre of Southeast Asian Studies. Melbourne: Monash University: 1-48.

Hardjasaputra, A.Sobana. 1985. Bupati-bupati Priangan; Kedudukan dan Peranannya pada Abad ke-19 Tesis tidak diterbitkan. Yogyakarta: Universitas Gadjah Mada.

Kartodirdjo, Sartono. 1973. Protest Movement in Rural Java; a Study of Agrarian Unrest in the Nineteenth and early Twentieth Centuries. London: Oxford University Press.

Kern, R.A. 1898. Geschiedenis der Preanger-Regentschappen; Kort Overzigt. Bandung: de Vries \& Fabricius.

De Klein, Jacob Worter. 1931. Het Preanger Stelsel (1677 - 1871) en zijn Nawerking. Leiden.

Leirissa, R.Z. (ed.). 1993. Nusantara di Abad ke-18 dan ke-19, dalam Marwati Djoened Poesponegoro dan Nugroho Notosusanto. Sejarah Nasional Indonesia. Jilid IV. Jakarta: Departemen Pendidikan dan Kebudayaan.

Van Meerten, Henri Charles. 1887. Overzigt van de Hervorming van het Preangerstelsel. Leiden: Goen.

Raffles, Thomas Stamford. 1817. The History of Java, 2 vols. London: Block Parbury and Allen and John Murry.

Suryo, Djoko. 1989. Sejarah Sosial Pedesaan Keresidenan Semarang 1830-1900. Yogyakarta: Pusat Antar Universitas-Studi Sosial Universitas Gadjah Mada.

Svensson, Thommy. 1983. Contractions and Expansions; Agrarian Change in Java since 1830. Gothenburg: The Historical-Antropological Project, Gothenburg University. 